290 Jungek: Verhalten der Auflösung ron molybdänsaurem Ammon etc.

Isländischer Doppelspath.

\begin{tabular}{|c|c|c|c|c|c|c|}
\hline \multicolumn{2}{|c|}{ Angewandt. } & \multicolumn{5}{|c|}{$\begin{array}{l}\text { Gefundene Kohlensäure } \\
\text { in Procenten. }\end{array}$} \\
\hline 0,899 & Grm. & . & . & . & 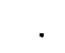 & . 43,44 berechnet 44,0 \\
\hline 1,0725 & $\ll$ & . & . & . & . & . 43,92 \\
\hline 0,9072 & $\ll$ & . & 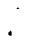 & 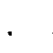 & 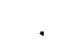 & - 43,92 \\
\hline 1,1015 & $\ll$ & . & . & . & . & . 43,93 \\
\hline 0,8595 & $\ll$ & ${ }^{\circ}$ & . & . & • & . 43,94 \\
\hline \multicolumn{7}{|c|}{ Reines gefälltes Baryumcarbonat. } \\
\hline 1,1756 & Grm. & & & . & & . 22,30 berechnet 22,32 \\
\hline 1,171 & « & . & . & . & 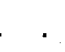 & . 22,31 \\
\hline 1,2795 & $\ll$ & . & . & $\therefore$ & . & $\begin{array}{l}\cdot \quad 22,29 \\
\end{array}$ \\
\hline 0,6740 & $\ll$ & . & . & . & . & . $\quad 22,30$ \\
\hline 0,8685 & $\ll$ & & . & . & . & . $\quad 22,31$ \\
\hline
\end{tabular}

Ueber das Verhalten der Anflösung von molybdänsaurem Ammon in. Salpetersäure zum Licht.

Von

\title{
M. Jungck.
}

Die zur Fällung der Phosphorsäure benutzte Lösung von molybdänsaarem Ammon in Salpetersäure setzt bei der Aufbewahrung fast stets einen intensiv gelben krystallinischen Niederschlag $a b$, auch wenn man dieselbe nach ihrer Bereitung 24-28 Stunden stehen gelassen und von der sich fast stets bildenden Trübung abfiltrirt hat. Derselbe bildet mit der Zeit fest zusammenhängende Schalen, die am Boden und den Gefässwänden festsitzen, sich in Ammon leicht lösen und sich überbaupt ganz wie der bekannte Niederschlag mit Phosphorsäure zu verhalten scheinen, für den sie auch häufig gchalten werden. Wiederholte Versuche haben dem Verfasser jedoch gezeigt, dass obiger Niederschlag, der sich auch nach vorheriger Filtration absetzt, keine Spur Phosphorsäure enthält, da selbst mehrere Gramm davon - in Ammon gelöst und mit Magnesiamischung versetzt - keinen Niederschlag gaben. Es scheint derselbe vielmehr lediglich eine andere Modification von Molybdänsäure zu sein, die durch die Einwirkung des Lichtes auf obige Lösung gebildet wird. Es empfiehlt sich daher die Molybdänlösung in Flaschen 
von möglichst dunklem Glase an vor Lieht geschützten Orten aufzubewahren. Hier hat sich die Menge des sich bildenden Niederschlags, seitdem statt der früheren Flasche von weissem eine solche von dunkelgelb-grünem Glase*) genommen wurde, ungemein vermindert. Dagegen entstand in einem Giase, welches mit einer schon wochenlang bereiteten, fast ganz klar gebliebenen und nochmals filtrirten Lösung einige Stunden dem directen Somnenlichte ausgesetzt wurde, eine starke sich stets vermehrende Trübung, während in einer mit eben dieser Lösung unter Abhaltung des Lichts gefüllten und daneben gestellten Flasche eine Trübung nicht entstand.

\section{Zur Ausfällung des Eisenoxyds und der Thonerde durch essig- saures Natron. \\ Vou \\ M. Jungok.}

Der mit essigsaurem Natron gefällte Niederschlag von Eisenoxyd und Thonerde ist oft nur schwer auszuwaschen, weil das basisch ressigsaure Eisenoxyd etc. die Filterporen verstopft, besonders wenn vorher nicht vollständig neutralisirt worden ist. Die Filtration ist dabei oft so langsam, dass das Waschwasser auf dem Filter kalt wird, in welchem Falle dann, wenn die Lösung noch zu sauer war, das Eisenoxyd durchläuft und durch nochmaliges Kochen abgeschieden werden muss. Diesem Uebelstande lässt sich jedoch leicht abhelfen, wenn man möglichst vollständig neutralisirt, ohne jedoch etwas zu fällen und dann zur gut am besten mit heissem Wasser - verdünnten Flüssigkeit s e h r viel essigsaures Natron ( $1 \frac{1}{2}-2$ Grm. auf 0,1 Grm. Eisenoxyd und Thonerde) fügt. Der Niederschlag setzt sich dann beim Kochen sofort vollständig $\mathrm{ab}$, ist grossflockig und braun and lässt sich ebenso rasch wie der mit Ammon gefällte auswaschen. Bei schlechter Neutralisation ist derselbe roth und pulverig, bei zu wenig zugesetztem essigsaurem Natron rothbraun und kleinflockig.

*) Eine ganz undurchsichtige Flasche zu nehmen, wäre zu unbequem, eine hinreichend grosse blaue Flasche war nicht zur Hand. 